\title{
Hibridismo cultural no espaço urbano: a São Paulo de Luiz Ruffato
}

\author{
Cultural hibrity on urban space: the São Paulo of Luiz Ruffato
}

\section{Lucas da Cunha Zamberlan \\ André Soares Vieira}

Universidade Federal de Santa Maria - UFSM - Santa Maria - Rio Grande do Sul - Brasil

\begin{abstract}
Resumo: Este artigo visa refletir sobre os mecanismos discursivos do romance Eles eram muitos cavalos, de Luiz Ruffato, evidenciando o fenômeno sociocultural do hibridismo como elemento fundamental na composição do espaço urbano de São Paulo. A fim de alcançamos o nosso objetivo, adequamos o estudo aos seguintes parâmetros metodológicos: a) análise rigorosa dos recursos estéticos manipulados pelo autor com o intuito de perceber como certas temáticas, tão relevantes ao debate do weltgefueh/social da América-Latina, são amalgamadas ao arcabouço do romance; b) compreensão do hibridismo como conceito-chave na configuração tanto das relações interpessoais entre os habitantes da metrópole, quanto da organização dos fragmentos, conferindo unidade à narrativa; $\mathrm{c}$ ) fortuna crítica de autores oriundos da teoria literária eda sociologia na tentativa de promover o diálogo das esferas do conhecimentos que abalizam esta pesquisa científica. Para tanto, construímos um aporte teórico que sevaleu dos apontamentos de Canclini (2013), Calvino (2010), Bauman (2001), (2009), Canevacci (1996), Bakhtin (2012), Giddens (2008), Landowski (2002), entre outros.A partir dos constituintes avaliados, concluímos que o hibridismo sociocultural que compõe o cenário das grandes cidades latino-americanas coadunase com o próprio experimentalismo de formas do romance, apontando um caminho onde a multiplicidade e heterogeneidade assumem um papel fundamental.
\end{abstract}

Palavras-chave: Hibridismo. São Paulo. Luiz Ruffato. Eles eram muitos cavalos.

Abstract: This article aims to reflect about the discursive mechanisms of the novel Eleserammuitoscavalos, by Luiz Ruffato, showing the sociocultural phenomenon of hybridity as a key element in the composition of urban space of São Paulo.In order to reach our goal, we suited the study to the following methodological parameters: a) accurate analysis of aesthetic resources manipulated by the author in order to understand how certain themes so relevant to debate the social weltgefuehl of LatinAmerica, are consolidated to framework of the novel; b) comprehension of hybridity as a key concept in the configuration of both interpersonal relationships between inhabitants of metropolis, and the organization of fragments, giving unity to the narrative; c) literary criticism from literature theory and sociology in attempt to promote dialogue of the spheres of knowledge that support this scientific research.To achieve our hypotheses, findings and questions, we constructed a theoretical framework that Canclini (2013), Calvino (2010), Bauman (2001), (2009), Canevacci (1996), Bakhtin (2012), Giddens (2008), Landowski (2002), among others. From analyzed constituents, we conclude that socio-cultural hybridity that compose the setting of large Latin American cities is consistent with experimentation of the novel forms, pointing a path where multiplicity and heterogeneity play a key role.

Keywords: Hybridity. São Paulo. Luiz Ruffato. Eles eram muitos cavalos. 


\section{Introdução}

NON DVCOR DVCO

(Não sou conduzido, conduzo)

Divisa encontrada no brasão da cidade de São Paulo

O livro Eles eram muitos cavalos, primeiro romance do escritor Luiz Ruffato, é constituído por sessenta e nove capítulos - relativamente independentes -que entrelaçam vidas anônimas que vagam pelo maior centro urbano da América do Sul. $A$ estrutura fragmentária da obra endossa a intenção do autor de tentar abranger simultaneamente a multiplicidade e heterogeneidade da metrópole paulistana, ressaltando a variedade de elementos que compõe a paisagemda cidade. Além disso, cada passagem atuacomo uma situação metonímica que sugere outras muitas situações e realidades semelhantes.

Em contrapartida, por mais reveladora e eficaz que essa estética se demonstre na apreensão da totalidade da urbe, ela esbarra na própria impossibilidade de dimensionar, na sua integralidade, o espaço metropolitano. Sá (2007) reflete sobre essa questão:

O leitor sabe que os 69 fragmentos são apenas um pequeno número entre muitos outros possíveis, pois se passam em uma área urbana de aproximadamente vinte milhões de pessoas. Os 69 fragmentos assumem esse conhecimento por parte do leitor: eles existem para serem apenas uma porção de algo muito maior (SÁ, 2007, p. 9495).

Mesmo que o leitor não conheça a metrópole por completo, ele não precisa percorrer todos os corredores deste labirinto concretado para conhecê-la por inteiro. Para Bauman (2001, p. 121-122), cada habitante de uma grande cidade tem o seu mapa urbanizado na cabeça. Tais projetos geográficos são repletos de espaços vazios, pois representam os lugares ignorados pelo morador em questão: "para que qualquer mapa 'faça sentido', algumas áreas da cidade devem permanecer desconhecidas. Excluir tais lugares permite que o resto brilhe e se encha de significado".

O apontamento do teórico se faz plenamente compreensível, afinal, baseando-se pelos dados do Instituto Brasileiro de Geografia e Estatística (IBGE), os números de São Paulo impressionam. A metrópole

é a cidade mais populosa do continente sulamericano e de todo o hemisfério sul, além de também ser a sexta mais populosa do mundo. Em $1.521,101 \mathrm{~km}^{2}$, a área territorial da capital, desconsiderando suas cidades satélites, era habitada, no ano de 2000, por mais de dez milhões de pessoas. Hoje, ela também é considerada a quarta maior aglomeração urbana do planeta e também possui o décimo maior PIB do mundo, representando, isoladamente, $11,5 \%$ de todo o PIB brasileiro.

Embora esses milhões de habitantes coexistam no mesmo universo territorial, a tendência não é de homogeneização dos traços culturais, muito pelo contrário. Conforme o sociólogo Giddens (2008), muitos teóricos acreditam que ocorra, atualmente, uma definitiva diferenciação nas mais diversas esferas sociais que torna o espaço metropolitano plural e desagregado:

Outros autores, pelo contrário, associaram os processos de globalização a uma crescente diferenciação no que diz respeito a formas e tradições culturais. Ao contrário dos que insistem no argumento da homogeneização cultural, esses autores afirmam que a sociedade global se caracteriza atualmente pela coexistência lado a lado de uma enorme diversidade cultural (GIDDENS, 2008, p. 64).

Esse panorama, no qual a diferença torna-se a marca principal da composição urbana, favorece o intercâmbio de culturas. Dessa forma, a partir dos apontamentos teóricos sobre hibridismo sociocultural, será possível compreender melhor o weltgefuehl dos grandes centros da América Latina, bem como os caminhos da narrativa no século XXI.

\section{Uma cidade múltipla}

Canclini (2013), no livro Culturas híbridas, pensa sobre essa realidade caoticamente heterogênea ao considerar a hibridação, ou seja, o 
intercâmbio sociocultural, como um fenômeno irrefreável, crescente e de especial importância na compreensão do ethos das principais cidades da América Latina. Canclini (2013, p. XIX) define o termo analisado como "processos socioculturais nos quais estruturas ou práticas discretas, que existiam de forma separada, se combinam para gerar novas estruturas, objetos e práticas". Além disso, ele estende 0 conceito a diferentes esferas do conhecimento e,a fim de comprovar suas reflexões, traz outros estudos realizados por pensadores contemporâneos:

Ele é usado para descrever processos interétnicos, e de descolonização (Bhabha, Young); globalizadores (Hannerz); viagens e cruzamentos de fronteiras (Clifford); fusões artísticas, literárias e comunicacionais (De la Campa; Hall; Martin Barbero; Papastergiadis; Webner). Não faltam estudos sobre como se hibridam gastronomias de diferentes origens na comida de um país (CANCLINI, 2013, p. XVIII).

Dentre as apresentações de processos dos mais variados, as fusões artísticas a que se refere o teórico coadunam-se com a prosa de diversos autores contemporâneos, que, no afã de representar esse hibridismo cultural, lançam mão de técnicas narrativas inovadoras, estabelecendo uma comunhão com o espaço que descrevem nas suas obras. Calvino (2010), no ano de 1989, propôs qualidades literárias que deveriam ser valorizadas no século XXI, já percebendo, naquele contexto, uma das marcas indeléveis da contemporaneidade, que já vinha em processo de franca emergência nas últimas décadas do século passado:

Nesta conferência creio que as remissões às literaturas do passado podem ficar reduzidas ao mínimo, ao quanto basta para demonstrar como em nossa época a literatura se vem impregnando dessa antiga ambição de representar a multiplicidade das relações, em ato e potencialidade (CALVINO, 2010, p. 127).

A prosa de Ruffato se insere como um modelo de hibridismo na literatura, pois apresenta, em Eles eram muitos cavalos, uma estética que em diferentes aspectos reflete sobre o pluralismo do espaço urbano e, sem dúvida, coloca-o em primeiro plano. Tal traço temáticoharmoniza-se com as ideias de Canclini (2013) que constata, nas grandes cidades, o ambiente onde o hibridismo triunfa com maior força:

As megalópoles multilíngues e multiculturais, por exemplo, Londres, Berlin, NovaYork, Los Angeles, Buenos Aires, São Paulo, México e Hong Kong são estudadas como centros em que a hibridação fomenta maiores conflitos e maior criatividade cultural (CANCLINI, 2013, p. $X X X)$.

A partir do apontamento de Canclini (2013), verifica-se o inquestionável caráter híbrido de São Paulo, que, por sua vez, pode ser encontrado como manifestação artística nos mais variados capítulos do romance, constituindo-se assim como um reflexo da criatividade cultural apontada pelo teórico e intrinsecamente amalgamado ao arcabouço da obra.

No corpo de Eles eram muitos cavalos, há a alternância criativa de fontes, espaçamentos diferenciados, utilização inusitada de sinais gráficos, trechos ininterruptos de discurso, destaques em sublinhado, negrito e itálico, páginas pretas e colagens de elementos extraestéticos que se acumulam com o intuito de transmitir a variedade dos traços culturais que compõe a São Paulo representada. Assim, as próprias variações de tipologia textual disseminadas nos seus diversos capítulos constituem-se como norte abalizador para a sua compreensão. Segundo Bakthin (2012), cada meio de interatividade humana produz textos com características específicas. Com isso, estudar esses formatos significa aprofundar-se na análise de produções histórico-sócio-culturais existentes na sociedade.

Nos fragmentos Mãe e Carta, por exemplo, o gênero textual carta emerge como uma prática comunicativa entre mãe interiorana e filho morador da metrópole. No caso de Mãe, a carta aparece de forma sutil, incorporada em meio à descrição dos pensamentos da personagem:

[...] ganhar a vida em Sampaulo, no Brejo velho Duas vezes só, voltou, meu Deus, e isso em solteiro, depois, apenas os retratos 
carreavam notícias, o emprego, a namoradaagora-esposa, eles dois, a casa descostelada, os netos, e vamos então esperar a senhora para passar o dia das mães com a nossa familia e todos vamos ficar muito felizes não preocupa não que ew vou buscar a senhora na rodoviárialembranças a todos doa bexiga cachumbenta, o intestino goguento [...] (RUFFATO, 2013, p. 19).

O trecho, contudo, não é conclusivo, já que a parte destacada não oferece a certeza da utilização do gênero, pois as suas características não se demonstram de forma explícita. Diferente dessa passagem, em Carta, além do tom sentimental, há também todas as marcas especificamente linguísticas que caracterizam um texto do gênero, como data, linguagem coloquial, despedida e assinatura, além da reprodução de uma letra que imita a escrita à mão.

\section{Guidoval, 2 de maio de 2000 \\ Querido Paulino, mew fitho, \\ Escrevo-the estas mal traçadas \\ linhas para dar noticias nossas [...] \\ Beyjos meu fitho querido \\ Da sua mãe saudosa \\ que te ama,}

2013, p.91-92).

GlorinhakRUFFATO,

A comunicação entre mãe e filho também aparece de maneira semelhante em $A$ espera. Aqui, Ruffato realça uma diversificação verbal que não se restringe, novamente, ao campo de significação, mas que apela, como na passagem anterior, para uma modificação na fonte do texto, mimetizando no seu romance, a forma de um bilhete:

Na porta da geladeira, fixado por imãs (um abacate, um chuchu e a propaganda de uma farmácia), um bilhete:

Não vá perder a hora, meu amor.

Estou torcendo por você.

Boa sorte.

Berjo da

mamãe

Amassa o papel, enfia-o na lixeirinha que transborda cascas de banana na superfície molhada da pia (RUFFATO, 2013, p. 35).
Já em Ritual para a terça-feira, lua em câncer, o gênero escolhido é a simpatia. Sendo assim, o texto aparece repleto de verbos no imperativo, aliado a substantivos que remetem a um campo semântico ligado ao universo místico, como cristais, incensos e flores, indicando uma série de atitudes a serem tomadas pelo leitor, a fim de que seu desejo se concretize.Ademais, muitos outros capítulos se somam como modelos exemplaresna sedimentação do uso de diferentes gêneros textuais, como cardápios de restaurante, lista de empregos e diplomas de conclusão de curso.

No capítulo (ela, embora o fragmento seja breve, percebe-se uma explicitação da variedade encontrada na cidade por meio da descrição da rotina de uma personagem. Uma menina de dezesseis anos percorre as ruas da capital sem um objetivo concreto. Essa experiência urbana aparentemente simples acarreta na observação de uma paisagem marcada pelo entrecruzamento de elementos diferentes, oriundos dos lugares mais variados.

Para que consiga espaço para caminhar, a jovem tem de desviar dos objetos que são oferecidos pelos ambulantes e encontrar espaço entre brinquedos chineses, estojos de perfumes paraguaios, ervas medicinais, revistas, barracas de frutas e calças jeans. Experimenta um anel, mas consegue resistir à tentação de adquiri-lo e segue o seu caminho, sentindo o cheiro de gasolina e óleo diesel que vem da rua. $\mathrm{O}$ empilhamento de produtos faz com que ela tropece em uma caixinha de música que mistura a sua canção com outra, vinda de uma loja de departamentos. Ao mesmo tempo, um "moçotatuagens" polui a rua ao extrair de um instrumento tosco uma sucessão de dó-ré-mis. Quando sente fome, vai em busca de comida e, antes de escolher um churrasco-grego no pão, é assediada primeiramente em um coletivo e em seguida por um homem que the convida para realizar uma sessão de fotos. Entra em um shopping, onde é tratada por madame, e na sequência ganha a rua novamente. Enquanto se alimenta, conta os minutos para continuar o seu trajeto. 
Esse hibridismo cultural manifesto nos objetos também caracteriza os espaços por onde passa a jovem, pois não há limites definidos entre o pobre e o rico, o novo e o velho, o culto e o popular. A banca dos anéis baratos, por exemplo, fica em frente ao Teatro Municipal e o trem "medonho" lotado a leva para o Shopping Light, um dos maiores centros comerciais do Brasil, e suas dezenas de lojas finas estrangeiras frequentadas por pessoas da classe mais abastada. Tais contatos culturais, tão bem definidos nesse capítulo, recebem, de acordo com Canclini (2013), nomes diferentes:

A esta altura, há que dizer que o conceito de hibridação é útil em algumas pesquisas para abranger conjuntamente contatos interculturais que costumam receber nomes diferentes: as fusões raciais ou étnicas denominadas mestiçagem, o sincretismo de crenças e também outras misturas modernas entre 0 artesanal e o industrial, o culto e o popular, o escrito e o visual nas mensagens midiáticas (CANCLINI, 2013, p. XXVII).

O sincretismo de crenças, citado por Canclini (2013), como uma denominação das manifestações do hibridismo na esfera religiosa, é um dos processos culturais mais representativos na constituição dos conteúdos distribuídos nos capítulos de Eles eram muitos cavalos. Segundo Costa (2010), originalmente o sincretismo foi um conceito bastante utilizado para explicar um fenômeno religioso específico, ocorrido normalmente em países que sofreram processo de colonização. Nesses lugares, os povos colonizados eram obrigados a abandonar a sua religião e adotar a crença dos colonizadores. Com a finalidade de não perderem a sua identidade, esses povos adotavam a nova religião, porém, buscavam identificar os novos deuses com as divindades de sua cultura tradicional.

Canevacci (1996) faz um estudo aprofundado sobre o conceito, colocando-o, senão como um sinônimo de hibridismo, como um fenômeno que se assemelha muito com a mescla de processos socioculturais apontada por Canclini (2013), e o considera como 0 termo principal para a compreensão do universo contemporâneo:
Assumimos aqui o sincretismo como termochave para a compreensão da transformação que está se dando naquele processo de globalização e localização que envolve, transforma e arrasta os modos tradicionais de produção de cultura, consumo e comunicação (CANEVACCI, 1996, p.13).

Dessa forma, a observação de sincretismo sob a ótica de Canclini (2013), e principalmente de Canevacci (1996), permite aprofundar o conceito em questão e concebê-lo de forma mais ampla e abrangente, entendendo o pluralismo como fenômeno histórico-sócio-cultural fundamental na construção das relações humanas nas grandes cidades, não só na esfera religiosa, mas também na étnica e econômica.

O sincretismo, no sentido abrangente de hibridismo utilizado pelos dois teóricos, pode ser encontrado no capítulo Festa. Nele, Idalina faz uma visita à casa de uma amiga de infância. Vitimada pelo vírus do HIV contraído de seu próprio marido, a amiga de Idalina quer, pela primeira e última vez, ser maquiada pela única pessoa que mantinha um afeto por ela. Enquanto o desejo se cumpre, há a evidenciação do destino das duas, desde o primeiro encontro quando tinham doze anos, até aquele momento. Quando a personagem descobre que ela e o filho tinham AIDS, recorre, em um ato de desespero, a orações para santos de religiões diferentes:

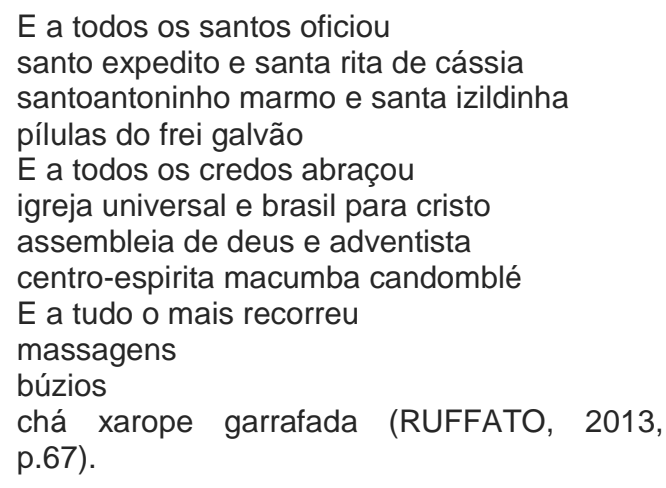

Essa passagem focada na coexistência de crenças diversas em uma só personagem é apenas uma demonstração do tema insistentemente trabalhado por Ruffato na obra. Mesmo antes da abertura do romance, em uma segunda epígrafe, após a citação do Romanceiro da Inconfidência, 
encontra-se um trecho do salmo 82: "Até quando julgareis injustamente a causa dos ímpios?". No capítulo 36, Leia o salmo 38, a passagem bíblica retorna como parte integrante de uma simpatia que tem por objetivo alcançar a realização de dois pedidos difíceis e um impossível de um leitor hipotético.

Já no terceiro capítulo, o autor lança mão da hagiologia para informar o santo do dia: Santa Catarina de Bolonha. Pelo fato de a santa ter dedicado sua vida no auxílio aos mais necessitados, a inserção desse fragmento pode vincular-se à ideia de uma possível proteção espiritual realizada pela santa aos habitantes da metrópole. Para Ricciardi (2007), a santificação, em Ruffato, está presente em toda a obra, pois se confunde com a própria cidade:

\begin{abstract}
A construção narrativa, assim como acontece, segundo Antônio Candido, com Vidas secas, de Graciliano Ramos, lembra um grande e colorido político, o típico quadro medieval, que tem na parte central a figura de um santo ou de Jesus Cristo ou de Nossa Senhora ou de um bem-aventurado, rodeada por cenas e quadros e figuras menores, contando acontecimentos, episódios e milagres de sua vida. Em nosso caso, a figura central é a cidade de São Paulo, rodeada e vivificada por estórias e personagens paulistanos, ainda que não de famílias quatrocentonas (RICCIARDI, 2007, p. 49).
\end{abstract}

As personagens do romance, de forma geral, parecem crer em um poder superior para superar seus problemas ou para explicar sua situação. De forma mais direta, no capítulo $A$ menina, encontra-se um casal que passa por dificuldades financeiras. Eles frequentam uma igreja todas as semanas:

O pai, emenda dias sem vê-lo. Técnico de aparelho-de-ar-condicionado, não tem hora para largar. A menina sabe, no entanto, que, no negror do quarto, ele aproxima os lábios de seu rosto, ajeita o cobertor, suspira. Aos domingos, fulgurante em seu melhor terno, a mãe enfeitada com seu mais caprichado coque, encaminham-se para o culto da igreja Deus é Amor, onde, junto a outras crianças, a menina especula sobre outras manhãs sepultadas na História Sagrada. (RUFFATO, 2013, p. 69)

No fragmento, o nascimento da menina, filha do casal, é acompanhado de toda a sorte de dificuldades, desde biológicas às econômicas, e é na fé que os pais encontram forças na tentativa de superar todos os problemas. Com efeito, a criança desenvolve-se dotada de beleza e inteligência. No final, o casal é comparado às figuras bíblicas de Sara e Abraão, reforçando a ideia de que as personagens acreditam na superação dos problemas pela crença.

Já em $O$ evangelista, um homem, em meio ao caos do centro de São Paulo, resolve fazer um discurso religioso em busca de novos fiéis para a igreja que frequenta. Em meio a desempregados, bêbados, mendigos, meninos drogados, batedores de carteira, o sujeito consegue chamar a atenção dos transeuntes, apesar das vozes, buzinas, motores, pregões e músicas. Logo no começo consegue reunir sete pessoas e, em pouco tempo, chega a reter a atenção de dezenas de ouvintes, sempre prometendo uma mudança na vida de quem seguir seu exemplo. No entanto, ele não consegue suportar o calor e desmaia, perdendo-se no chão entre tocos de cigarros, urina, pombos, papéis de balas e copos descartáveis.

A esperança dessas personagens anônimas em melhorar seus destinos auxilia na produção de elementos que compõe o Spätzeit, período de decadência que favorece esse acúmulo de elementos culturais que se aderem à paisagem urbana (MOSER, 1999). A colagem de um panfleto com a oração a Santo Expedito, em Fé, acaba sendo uma confirmação desses preceitos, pois a sua inserção no corpo do romance implica uma comunicação de caráter religioso entre o produtor do objeto e o leitor que o tem nas mãos. Por ser o santo das causas impossíveis, entende-se que somente por uma ação milagrosa realizada por ele, os objetivos podem ser alcançados.

Exatamente da mesma maneira, a análise astrológica do dia, enxertada no capítulo 7, orienta, através da influência dos astros, um comportamento a ser adotado por uma possível personagem. E essa promessa de uma vida melhor também se manifesta no horóscopo do capítulo 12 , nas simpatias dos fragmentos 36,49 e 60 . 
A temática religiosatambém é representada na colagem de um objeto tipicamente oriundo do Spätzeit: um diploma de batismo de uma igreja evangélica, datado de 1978, ou seja, vinte e dois anos antes de ser inserido no romance:

\section{IGREJA DO EVANGELHO QUADRANGULAR Cruzada Nacional de Evangelização}

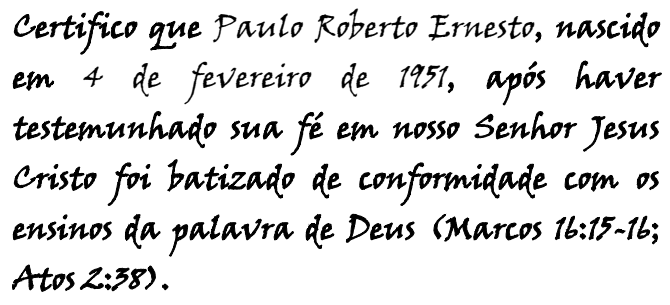

Ministro oficiante(RUFFATO, 2013, p.99).

Além das passagens trabalhadas, outras também se destacam ao abordar, cada uma com as suas especificidades, a pluralidade religiosa dos indivíduos da metrópole, muitas vezes hibridizadas na fusão de crenças diversas. Essa realidade influencia determinantemente os seus comportamentos, afinal acreditar em algo acaba tornando-se uma maneira de não se sentir totalmente desamparado às leis que a cidade determina. É o caso do senhor de $A$ vida antes da morte que, sabendo encontrar-se no último estágio de sua vida, tenta encontrar consolo em um livro espírita de Allan Kardec; do jovem que pede um milagre, em Slowmotion antes de ser provavelmente agredido em um jogo de futebol; ou até mesmo do desempregado, de Trabalho, que foge da família e dos vizinhos aos domingos, senta em frente à Assembleia Legislativa e pede a Deus que o mundo desmorone.

Como apontaCanclini (2013), além do sincretismo, há outro fenômeno causado pelo hibridismo e que está intrinsecamente ligado ao conceito referido: a mestiçagem. Esse fenômeno chega inclusive a assumir o mesmo significado do sincretismo quando abordado de forma mais ampla, como faz Canevacci (1996).
No capítulo O Crânio, esses conceitos de hibridismo e mestiçagem se refletem no texto. Nele, a personagem-narrador, morador de uma comunidade pobre, apresenta a sua família com a intenção principal de descrever o irmão, apelidado de "Crânio". Dessa forma, ele caracteriza cada um dos membros de acordo com seus traços físicos bastante diferentes entre si, resultantes do processo de uma miscigenação que, de certa maneira, representa o espaço metropolitano:

ele tem dezesseis anos quase um metro e setenta e cinco

[uns noventa quilos

é preto que nem a água preta que escorre no meio dos barracos

os dentes brancos e bons como os de ninguém

e principalmente ele é meu irmão

embora eu seja moreno puxado pro mulato baixo e faltando dentes

e tinha outro dos nossos mais pro louro sarará que até era esse o apelido dele sarará

e que já foi pipocado numa parada errada quando ainda de-menor (RUFFATO, 2013, p. 85-86).

Fenômeno semelhante ocorre na colagem do correio sentimental $\mathrm{Na}$ ponta do dedo (2), já que apresentaquinze pessoas dispostas a se corresponder com os leitores que se interessarem pelos seus perfis. Como a maioria dos indivíduos se descreve fisicamente, pode-se utilizar desse universo amostral a fim de verificar a natureza étnica e racial dos correspondentes. Cinco se denominam brancos, um, negro, um, pardo, um, moreno claro e outro se apresenta como nissei, o que indica a sua origem japonesa.

Em Onde estávamos há cem anos, o processo de estetização doethoshíbrido da cidade é notadamente característico. Há quatro planos narrativos que reconstroem as origens de uma personagem chamada Henrique que passeia pelas ruas da cidade em um carro de luxo. No entretempo do semáforo abrir, há uma volta ao passado da personagem, com a descrição do encontro dos seus avós paternos na região do Brás, em São Paulo: "O vênetoGiácomo enamorou-se da napolitana Maria, numa festa no Brás" (RUFFATO, 2013, p. 72). Após 
essa passagem, é a vez do lado materno ser explorado:

O avô materno, um bigodudo trasmontano, cabelos de azeviche amansados a Glostora, mãos lixentas enormes, um desengonço só, que desabava em lágrimas ao ouvir Amália Rodrigues, puxava carroça de casa em casa em Cangaíba [...]Ganhava a vida assim. A avó bugra de não falar língua de gente, de se esconder debaixo da cama, ninguém sabia de onde haviam laçado. A mãe de Henrique havia nascido desse desencontro (RUFFATO, 2013, p. 73).

Henrique, portanto, é o resultado de um processo de miscigenação que envolve italianos vindos de localidades diferentes, portugueses e indígenas que se encontraram em São Paulo.

Ainda deve-se ressaltar a maneira pejorativa com a qual a avó materna da personagem não só é denominada, a partir do termo bugre, mas como também é apresentada, com a reprodução de um discurso carregado de elementos discriminatórios que a colocam em um nível animalesco. Os trechos "não falar língua de gente" e "ninguém sabia onde haviam laçado" confirmam essa interpretação. Sendo assim, a passagem coaduna-se com o próprio percurso segregatício sofrido pelos indígenas em São Paulo e também no Brasil de uma forma geral.

O processo de miscigenação, como se pode perceber nesse e em muitos outros fragmentos da obra, não torna a convivência entre as personagens tolerante, visto que a segregação acaba compondo um dos traços mais marcantes nas relações entre os moradores da cidade. No livro Confiança e medo na cidade, Bauman (2009) reflete sobre o mundo globalizado e as tendências de comportamento social no universo das grandes metrópoles. Ao referir-se precisamente sobre São Paulo, o enfoque do autor dirige-se ao processo intenso de segregação e exclusão dos membros que o autor denominou pertencentes à "última fila", ou seja, os habitantes das classes menos favorecidas:

A tendência a segregar, a excluir, que em São Paulo (a maior conurbação do Brasil, à frente do Rio de Janeiro) manifesta-se da maneira mais brutal, despudorada e sem escrúpulos, apresenta-se - mesmo que de forma atenuada - na maior parte das metrópoles (BAUMAN, 2009, p.40).

A exclusão favorece um quadro no qual a insegurança e o medo tornam-se sentimentos constantes e a violência corriqueira. Para Landowski (2002, p.9), a exclusão leva à negação e, consequentemente à fúria, acelerando um caminho que acaba, inevitavelmente, na violência: "o discurso de exclusão procede de um gesto explicitamente passional que tende à negação do Outro enquanto tal. E uma vez acesa, sabe-se até que extremidades pode levar a fúria coletiva de ser Si".

No capítulo Um índio, ocorre um aprofundamento do tema, já que o autor aborda a segregação étnica sofrida por um indígena em São Paulo. O seu desenvolvimento se constrói de uma forma pungente, narrada por um sujeito que frequenta o mesmo botequim todos dos dias: o bar do Seu Aprígio. O lugar é descrito como um ambiente simples, pobre, espaço de reunião de homens com pouca escolaridade, o que se pode perceber pelo vocabulário do próprio narrador. Um dia, um índio esfomeado aparece no local, pedindo comida.

O fato de o índio pertencer a uma etnia diferente dos demais e falar outra língua o coloca em uma posição distinta, sendo recebido pelos frequentadores do bar como estrangeiro. No primeiro momento, ele desperta interesse dos homens justamente por apresentar um comportamento pitoresco, dessemelhante aos olhos do grupo de referência.

Conforme Landowski (2002), a diferença do Outro pode despertar, em um primeiro momento, interesse causado pelo estranhamento:

Quando muito, talvez ele (grupo de referência) atribua a algumas das esquisitices do estrangeiro um valor estético particular, ligado aos efeitos de estranhamento que elas exercem, justamente em virtude de seu estado de estrangeiro: administrado em dosagem moderada, o exotismo pode efetivamente ter seu encanto, como espetáculo a ser visto no local (LANDOWSKI, 2002, p.6).

O índio embebeda-se e depois se despe, chamando a atenção de toda a comunidade. Todos 
parecem se divertir com a cena exótica. Em seguida, ele acaba preso pela polícia, sofrendo violência física. Passados alguns dias, ele reaparece, pedindo comida novamente. Seu Aprígio, dono do botequim, aceita a aproximação, embora comece a explorá-lo.

Os frequentadores começam a chamar o índio de Peri, estabelecendo uma alusão ao personagem mítico do livro O Guarani, de José de Alencar. No entanto, o "Peri" de Ruffato não consegue manter nenhum traço de semelhança com o "Peri" de Alencar, a não ser a etnia. A personagem romântica foi criada como modelo de herói romanesco que encarnava as virtudes do indivíduo natural do Brasil, ou seja, o seu melhor representante. Nesse sentido, o fragmento é emblemático, pois assinala não só a marginalização do indígena nas grandes cidades, mas também a finalização de um processo de exclusão social de contornos irreversíveis.

Em troca de alimento, Peri fica encarregado da limpeza do estabelecimento, além de conseguir a permissão de poder dormir na calçada em frente ao portão. Seu Aprígio pensa que "Pelo menos, arrombar ninguém vai querer" (RUFFATO, 2013, p.31). A relação entre o índio e o dono do bar é ambígua. Seu Aprígio assume, paradoxalmente, uma figura de homem solidário e explorador. Sem sua ajuda, o índio passa fome, com ele, vive em regime de escravidão.

O Peri contemporâneo é um segregado, privado das mínimas condições para o convívio social. Não possui dinheiro nem casa. Não consegue estabelecer uma comunicação eficiente e, ademais, o seu único objeto de afeto é o próprio explorador, pois quando Seu Aprígio morre, ele fica inconsolável.

\section{Conclusão}

Dessa maneira, considerando todos os fenômenos socioculturais que foram debatidos, percebemos a forma criativa e simultânea com que os múltiplos capítulos se congregam com a finalidade de revelar a pluralidade da cidade de São Paulo, comprovando que a sua unidade só pode ser representada pela variedade e pelo hibridismo.
Já em relação às aporias que essa organização social constrói pela sua própria mecânica, a fragmentação formal da obra que, de alguma maneira, questiona os limites do romance,é uma maneira de promover, por meio da linguagem, uma reflexão sobre o weltgeschichte da cidade latinoamericana contemporânea. A conclusão evidente é da irreversibilidade desse processo e, quando se faz necessário a construção de ideias como possíveis soluções para toda essa problemática, o único caminho parece estar contido no próprio texto: "precisaríamos reinventar uma civilização" (RUFFATO, 2013, p. 34).

\section{Referências}

BAKHTIN, Mikhail. Estética da criação verbal. São Paulo: Martins Fontes, 2012.510 p.

BAUMAN, Zygmunt. Modernidade líquida. Rio de Janeiro: Jorge Zahar, 2001. 260 p.

; tradução Eliana Aguiar. Confiança e medo na cidade. Rio de Janeiro: Jorge Zahar, 2009. 93 p.

CALVINO, Italo. Seis propostas para o próximo milênio. São Paulo: Companhia das Letras, 2010.141 p.

CANCLINI, Nestor; tradução Ana Regina Lessa e Heloísa PezzaCintrão. Culturas híbridas.São Paulo: Editora da Universidade de São Paulo, 2013. 385 p.

CANEVACCI, Massimo. Sincretismos:uma exploração das hibridações culturais. São Paulo: Nobel, 1996. $104 \mathrm{p}$.

COSTA, Cristina. Sociologia:questões da atualidade. São Paulo: Moderna, 2010. 342 p.

GIDDENS, Anthony. Sociologia.Lisboa: Fundação CalousteGulbenkian, 2008. 847 p.

IBGE. Censo Demográfico 2010. Disponível em: <http://www.censo2010.ibge.gov.br>. Acesso em: 10 mar. 2015.

LANDOWSKI,Eric. Presenças do outro. São Paulo: Perspectiva, 2002. $215 \mathrm{p}$.

MOSER, Walter. Spätzeit. In: MIRANDA, Wander Melo (org). Narrativas da modernidade. Belo Horizonte: Autêntica, 1999. 33-54 p.

RICCIARDI, Giovanni. Pedras para um mosaico. In: HARRISON, Marguerite Itamar (org). Uma cidade em camadas. Vinhedo: Horizonte, 2007. 48-53p. 
RUFFATO, Luiz. Eles eram muitos cavalos.São Paulo: Companhia das Letras, 2013. 136 p.

SÁ, Lúcia. Dividir, multiplicar, repetir: a São Paulo de Luiz Ruffato.In:HARRISON, Marguerite Itamar (org). Uma cidade em camadas. Vinhedo: Horizonte, 2007. 92-102p. 